\title{
THE CARDIOCIRCULATORY EFFECTS OF UPPER THORACIC EPIDURAL ANALGESIA*
}

\author{
Paul E. OtTon, M.D., F.R.C.P.(c) and Edith J. WiLson, M.D., Ch.B., D.A. $\nmid$
}

THE IMPORTANce of spinal and epidural analgesia in reducing peripheral venous and arteriolar tone is well appreciated. ${ }^{1-4} A$ less well-known but important additional factor is the haemodynamic effect produced by sympathetic denervation of the heart. Our attention was drawn to the cardiac implications of epidural sympathetic denervation by a recent clinical observation reported from this hospital by MacLean $^{5}$ (patient \#6) that lumbar epidural analgesia, in a patient in cardiocirculatory shock, precipitated a cardiac deficit.

Alterations in cardiac performance following sympathectomy have been noted in several previous physiological studies, either by the use of surgical cardiac denervation in $\operatorname{dogs}^{\theta, 7}$ or by examining the effects of antiadrenergic drugs in humans.,9 It is unknown to what extent the conclusions of these investigations can be applied to the regionally anaesthetized man. Furthermore, earlier haemodynamic investigations of conduction analgesia have failed to distinguish clearly the peripheral vascular from the cardiac effects. ${ }^{1-4}$ This deception may result from the usual clinical technique of initiating subarachnoid or epidural analgesia in the lumbar region and extending it cephalad, so that any direct cardiac effect is obscured by the unavoidable major denervation of peripheral vascular beds.

It is technically feasible to reduce the interference from the peripheral circulation and thus isolate the cardiac component by introducing an in-dwelling catheter into the epidural space at the upper thoracic level, then by selecting a proper mass of local analgesic ${ }^{10}$ to restrict the analgesia to the upper four or five thoracic nerves that contain the cardiac sympathetic fibres. This method of cardiac sympathetic blockade without gross denervation of the peripheral circulation provides a convenient method of studying the role of reduced cardiac sympathetic tone on myocardial function in humans. Accordingly, the present investigation was undertaken to isolate and identify the extent of cardiocirculatory changes to be expected following upper thoracic epidural sympathetic blockade.

\section{METHODS}

The investigations were carried out on six fit, non-sedated adult patients before operation. All studies were performed with the subject in the supine position, at rest in a quiet room; each subject was familiarized with the experimental procedures.

"Presented in part at the Annual Meeting of the Canadian Anaesthetists" Society at Banff, June 1966. This investigation was supported in part by a U.S.P.H.S. Grant and the Medical Research Council, Grant MA 1008.

tDepartment of Anaesthesia and Department of Surgery, McGill University and the Royal Victoria Hospital, Montreal. 
An in-dwelling polyvinyl epidural catheter was inserted through a modified Tuohy needle at the seventh cervical-first thoracic interspace; injection of any local analgesic was withheld. Arterial blood pressure was measured directly through an 18-gauge Rochester plastic cannula in a radial artery at the wrist. This was connected to a Sanborn no. 267-B pressure transducer and Sanborn no. 321 portable two channel recorder. The other channel recorded lead II of the electrocardiogram.

The central venous pressure was measured on a simple saline manometer connected to a 16-inch polyvinyl catheter (Sterilon) threaded into the superior vena cava by way of a 13-gauge Buffalo plastic cannula in an antecubital vein. The zero reference point for all pressures was a point $5 \mathrm{~cm}$. posterior to the sternal angle.

Cardiac output was measured by the indicator dilution method of Stewart and Hamilton using a $2.5 \mathrm{mg}$. $/ \mathrm{ml}$. concentration of indocyanine (Cardiogreen). Rapid central injection of the dye was made through the central venous pressure catheter from a syringe fixed to deliver a known and exact volume, repeatable within one per cent, and was followed immediately by a saline flush. Constant aspiration by a Harvard infusion-withdrawal pump (model 600-910/920) from the radial artery, was begun before the injection and fed through a Gilford densitometer (Gilford instruments, model I03 IR). The densitometer output was fed simultaneously into a computer (Lexington Instrument Corporation, model 303) and one channel of a Westronics two-channel recorder, the second channel receiving the output of the computer.

Pilot experiments revealed that cardiac output varied by less than 7 per cent from those calculated by the direct Fick method. A comparison of 25 cardiac outputs calculated by hand and by this computer gave a correlation of $0.95 .^{5}$ In this study duplicate cardiac outputs were measured on 12 occasions; the standard deviation of the differences between these determinations was $113 \mathrm{ml}$. per minute, or 2.3 per cent of the mean value of the cardiac output.

The hydrogen ion concentration $(\mathrm{pH})$ and tensions of oxygen $\left(\mathrm{P}_{\mathrm{O}_{2}}\right)$ and carbon dioxide $\left(\mathrm{P}_{\mathrm{CO}_{2}}\right)$ were measured using an IL micro $\mathrm{pH}$ and blood gas analysing system (Instrumentation Laboratory Inc., model 113-S2) during the control period and after epidural blockades. The sympatho-galvanic response (S.G.R.) $)^{11}$ as an index of electrical sympathetic activity, was assessed using a standard lead of the electrocardiogram. The presence of slow electrical waves demonstrated the existence of normal sympathetic tone in both the upper and lower limbs before epidural blockade; its absence in the upper limb after blockade confirmed a satisfactory sympathetic block in the upper thoracic region.

Following insertion of all the catheters and cannulae, the subjects rested quietly for at least thirty minutes. Duplicate control values of the arterial and central venous pressure, heart rate, and cardiac output were then established. The S.G.R. was tested in an arm and leg. A predetermined mass of plain 1 per cent mepivicaine (approximately $1 \mathrm{mg} . / \mathrm{kg}$. body weight), calculated to involve the smaller preganglionic flbres of the appropriate upper thoracic segments, ${ }^{10}$ was then injected through the epidural catheter. This concentration of local analgesia was below that expected to produce any significant somatic motor block or direct vascular reaction. The onset of cutaneous analgesia above the fourth thoracic 
dermatome, accompanied by clinical and objective electrical evidence of sympathetic loss in the head and arm, assured a sympathetic block of the thoracic viscera. Duplicate determinations of all parameters were repeated in thirty minutes when the cardiocirculatory system had become steady.

\section{Calculations}

\section{Systemic Resistance (Rs)}

Rs $\left(\right.$ dynes sec. cm. $\left.{ }^{-5}\right)=\left(P_{a}-\right.$ C.V.P. $\left.(\mathrm{mm} . \mathrm{Hg}) \times 1332 \times 60\right) /$ C.O. $(\mathrm{ml} . / \mathrm{min}$.

2. Left ventricular minute work index (kilogramme metres per square metre B.S.A.) was calculated as the product of cardiac index (litres per minute per square metre) and mean arterial pressure (centimetres water) divided by 100 .

3. Left ventricular stroke work index (gramme metres per square metre B.S.A.) was calculated as the product of stroke volume index (millilitres per square metre) and mean arterial pressure (centimetres water) divided by $100 .\left(\mathrm{P}_{\mathrm{a}}=\right.$ mean arterial pressure in radial artery; C.V.P. = central venous pressure; $\mathrm{C.O} .=$ cardiac output; cardiac index (C.I.) = C.O. litres per minute per square metre B.S.A.; B.S.A. = body surface area.

\section{Results (Table I and Figure 1)}

When compared to the mean values obtained at rest in the control state, upper thoracic epidural block resulted in a small but significant decrease in minute cardiac output. Cardiac index fell from 3.23 to $2.7 \mathrm{~L} . / \mathrm{min} . / \mathrm{m}^{2}(p<0.01)$, whereas the mean central venous filling pressure rose significantly from $4.2 \mathrm{~cm}$. $\mathrm{H}_{2} \mathrm{O}$ to $6.1 \mathrm{~cm} . \mathrm{H}_{2} \mathrm{O}(p<0.01)$. The reduction in minute output was positively correlated $(r=0.86, p<0.05)$ with the significant decrease in heart rate ( 81.5 to $68, p<0.05$ ), whereas the mean stroke volume index showed no consistent significant change ( $41.6 \mathrm{ml} . /$ beat $/ \mathrm{m}^{2}$ compared to $41.2 \mathrm{ml} / \mathrm{beat} / \mathrm{m}^{2}$ ). The mean arterial pressure was significantly less after the epidural block $(88 \mathrm{~mm} . \mathrm{Hg} \mathrm{com}$ pared to $96.2 \mathrm{~mm} . \mathrm{Hg}, p<0.02$ ), though the calculated total systemic vascular resistance increased significantly to 1513 dynes sec.cm. ${ }^{-5}$ compared to 1405 dynes sec.cm. ${ }^{-5}$. The minute and stroke work indices of the left ventricle paralleled the changes in volume output, there being a significant reduction of the minute work index to $3.23 \mathrm{~kg} .-\mathrm{m} . / \mathrm{min} . / \mathrm{m} .{ }^{2}$ from $4.19 \mathrm{~kg} .-\mathrm{m} . / \mathrm{min} . / \mathrm{m}^{2}(p<0.01)$, whereas the stroke work index did not change significantly $\left(60.6 \mathrm{gm} .-\mathrm{m} . / \mathrm{stroke} / \mathrm{m} .{ }^{2}\right.$ compared to $57.5 \mathrm{gm} .-\mathrm{m} . /$ stroke $/ \mathrm{m}^{2}$ ). The arterial blood $\mathrm{pH}$ and tensions of oxygen and carbon dioxide were essentially unaltered from the control values.

\section{Discussion}

The most significant and consistent cardiocirculatory change observed following upper thoracic epidural block was a decline in minute cardiac output associated with an elevation of the central venous pressure (Fig. 2). This failure of the cardiac output to respond to an increase in filling pressure suggested that a 


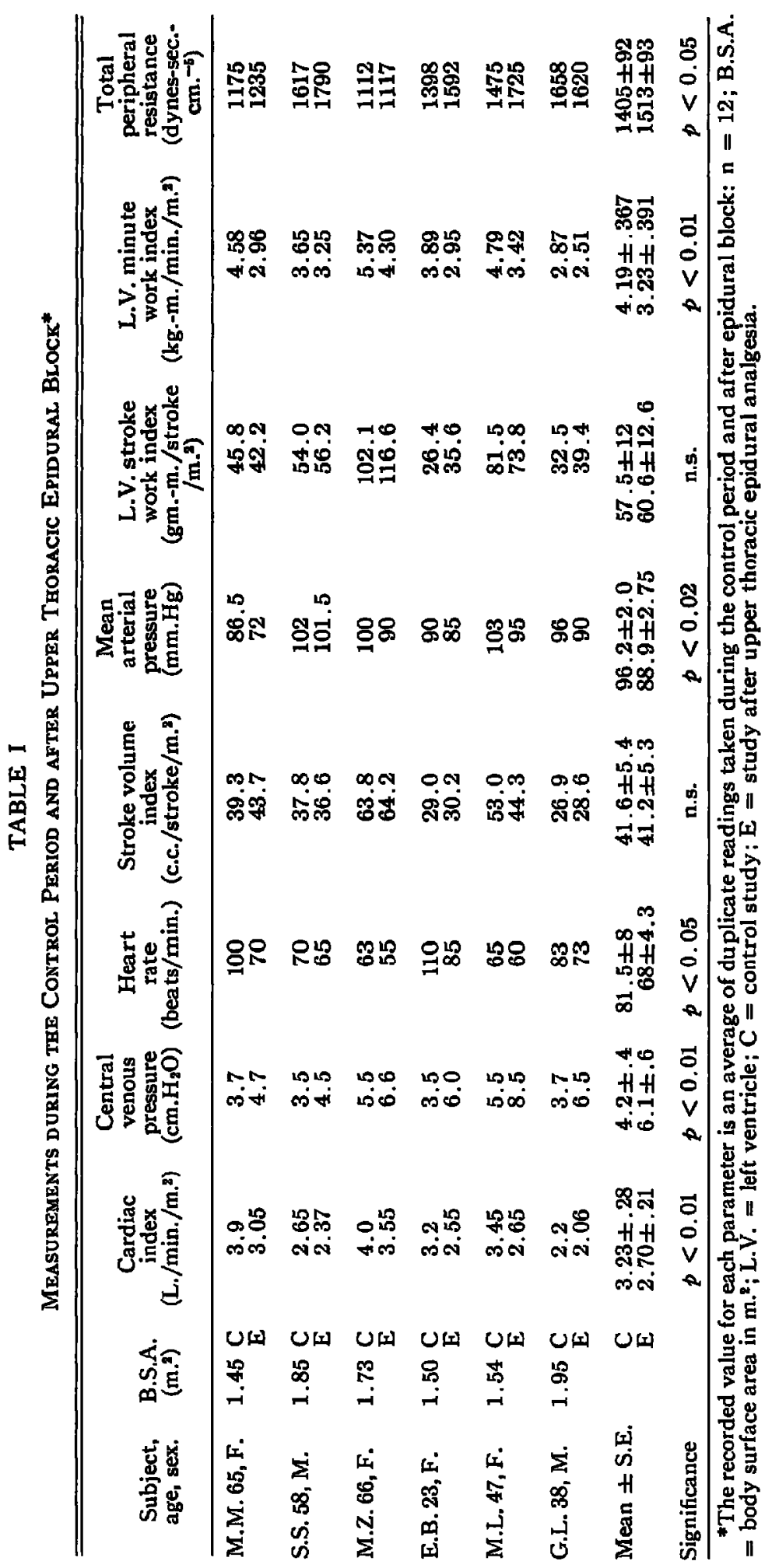




\section{CIRCULATORY CHANGES FOLLOWING UPPER THORACIC EPIDURAI BLOCK}
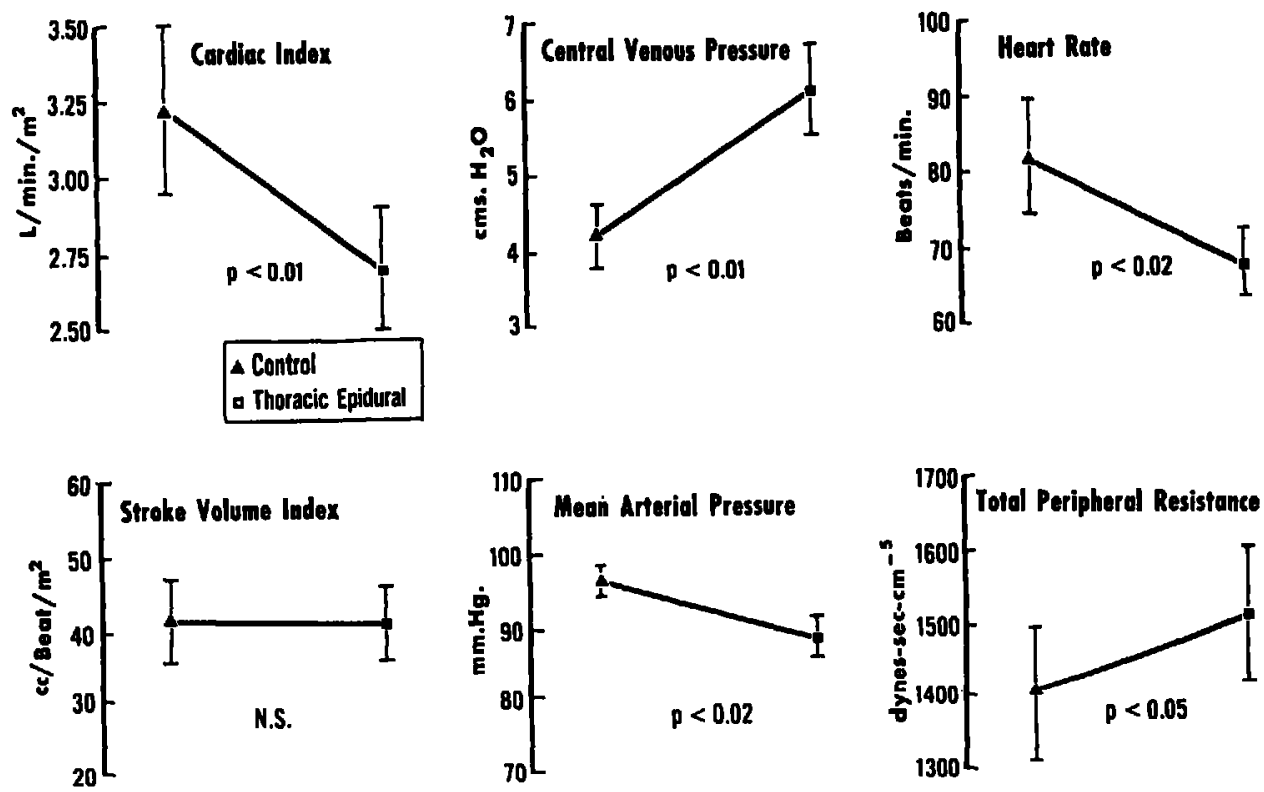

Ficure 1. A comparison of the haemodynamic measurements and calculations made before and after upper thoracic epidural block. The mean values are shown for each variable; vertical bars represent \pm standard error of the mean, $n=6$.

decrease in myocardial performance was fundamental to many of the observed cardiocirculatory changes. The simplest cardiac expression of the minute output is given by the product of the heart rate and stroke volume; the stroke volume output in turn is dependent on the pressure filling the heart during diastole and the contractile force emptying it during systole. An uncompensated failure of one or more of these basic mechanisms will decrease cardiac minute output.

In this series of experiments, a slowing of the heart rate was a consistent finding and served as a useful guide to the onset of cardiac sympathetic blockade. Furthermore, this bradycardia bore a direct and significant correlation to the reduction in minute cardiac output, and accounted for most of the decrease in minute flow as the stroke volume remained unchanged.

Changes in heart rate are known to be governed chiefly by the balance of parasympathetic and sympathetic tone existing at any moment. ${ }^{12}$ Previous interpretations of the bradycardia following traditional forms of spinal or epidural analgesia have emphasized that a vagal dominance secondary to a decrease in venous pressure (Bainbridge reflex) is of more importance than cardiac sympathetic denervation in the control of heart rate. ${ }^{1,3}$ It is unlikely that the same reflex autonomic adjustments could apply to the situation following upper thoracic analgesia, as the venous filling pressure rose in each instance. Indeed the expected response of the venous pressor receptors to the rise in central venous pressure, and of the arterial baroreceptors to the fall in arterial pressure, would be for both 


\section{CARDIAC RESPONSE TO UPPER THORACIC EPIDURAL BLOCK}

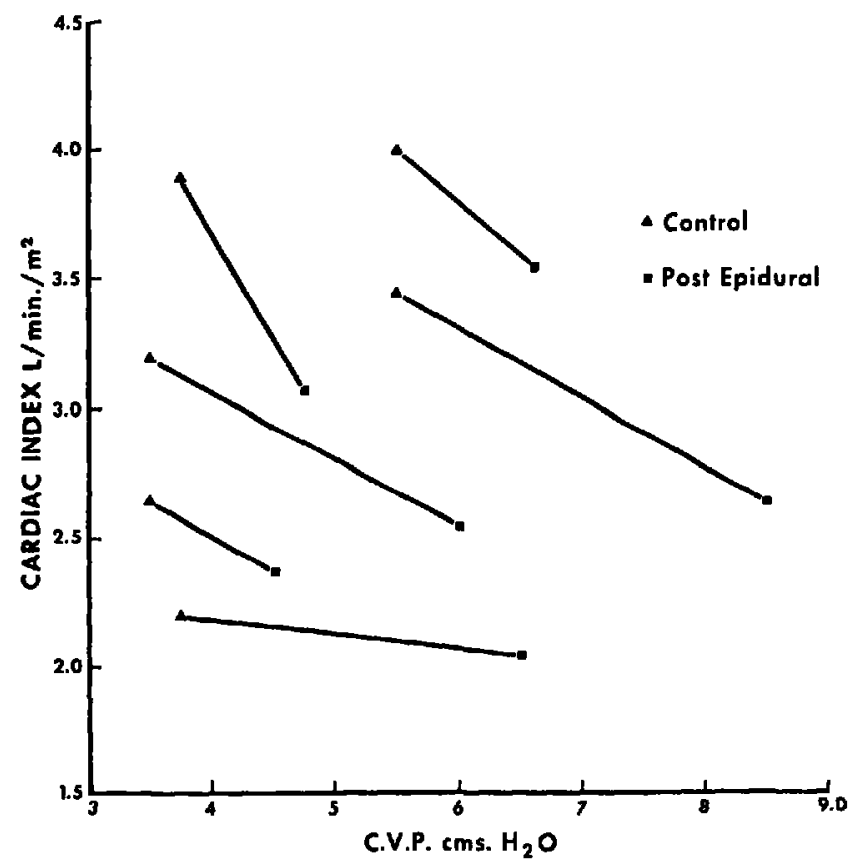

Frgure 2. Correlations of minute cardiac index response to central venous pressure for each case, before and after upper thoracic epidural block. There is a consistent shift of the cardiac response curve to the right.

to act in concert to decrease vagal tone while increasing sympathetic activity. ${ }^{12,18}$ Further argument in support of a reflex dominance of the sympathetic division was provided by the observed increase in calculated systemic vascular resistance. This increase in sympathetic activity acted only on the peripheral vessels below the segmental epidural block and was unable to excite the myocardium directly. Thus it would seem most likely that the decrease in heart rate following upper thoracic epidural block resulted from simple cardiac sympathetic deprivation. This bradycardia contributed significantly to the decrease in minute cardiac output.

The reduced minute flow from the heart was made even more conspicuous by the lack of compensatory increase in stroke output. It is well established that the stroke volume performance of the heart is dependent on two important regulatory mechanisms: ${ }^{14}$ the Frank-Starling mechanism, which responds positively to the stretch of ventricular filling pressure; and the degree of catecholamine stimulation which governs the level of this response. A significant increase in central venous filling pressure followed each epidural block, but it failed to increase the stroke volume output. The response of the sympathectomized myocardium, for a given filling pressure, was shifted to a sufficiently low level that the compensatory increase in filling pressure was now just adequate to maintain the stroke volume at the pre-block level (Fig. 3). It is of interest that a similar response of the 


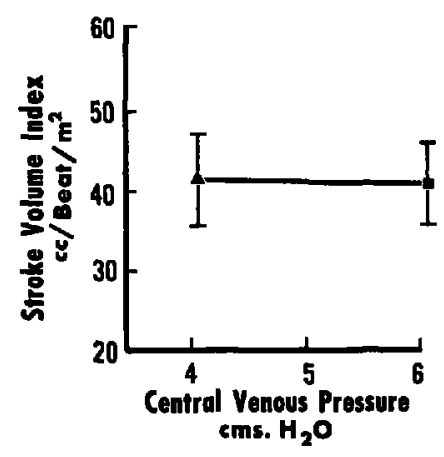

Frcure 3. Stroke volume response to central venous pressure. Mean values taken before and after upper thoracic epidural block; symbols as for Figures 1 and 2.

myocardium to beta-adrenergic blockade (propranolol) has been noted by Epstein and Braunwald, ${ }^{8}$ and confirmed by Sonnenblick ${ }^{15}$ to be a reduction in myocardial contractility. A second consequence, therefore, of epidural cardiac denervation was the damping of the normal response of the myocardium to its filling pressure: the heart filled better but emptied less well. ${ }^{6}$

The observed fall in mean arterial pressure can be explained entirely by the reduction in cardiac output, since the calculated mean systemic vascular resistance showed a significant elevation.

It is of interest to note that the persistence and elevation of arteriolar resistance demonstrated that a major part of the systemic circulation remained neurologically intact. Furthermore, the response pattern of the capacitance vessels could be expected to parallel that of the resistance segments. ${ }^{16}$ This effect would minimize a peripheral failure of venous return as a factor in reducing cardiac output.

Thus, the reduction in cardiac output following upper thoracic epidural block was primarily of cardiac origin. The defect appeared to derive from interference with two fundamental cardiac mechanisms: firstly, by slowing the heart rate, and secondly, by reducing myocardial contractility.

The changes outlined occurred under basal conditions and lend support to the view that the sympathetic nervous system exerts some tonic influence even at rest. ${ }^{8}$ However, the adrenergic nervous system assumes greater importance under clinical conditions of circulatory stress. The precise clinical implications of high thoracic epidural blockade in damping cardiac performance require further investigation.

It is known that adrenergic support of myocardial function increases whenever a potential imbalance exists between the perfusion requirements of the tissues and the cardiac output. ${ }^{17}$ Pharmacological beta-adrenergic blockade of the myocardium has been shown to impair the circulatory response to exercise, ${ }^{8}$ and to aggravate the existing myocardial depression of congestive heart failure.17,18 Likewise, the progression of circulatory shock, ${ }^{10}$ tolerance to hypoxia, the stress of 
rapid blood loss and replacement, ${ }^{20}$ and the postoperative ability to survive severe surgical trauma and infection ${ }^{21}$ are all governed to a degree by the calibre of the myocardial response. Upper thoracic epidural analgesia would be expected to dampen this response.

It is also clinically worth noting that cardiac sympathetic blockade can occur with something less than total spinal sensory block, as the extent of sympathetic analgesia may exceed the clinical somatic sensory distribution by two to six segments during spinal anaesthesia. ${ }^{1}$ Considering the recent theories on the site of action of epidural analgesia, ${ }^{22}$ a similar broad sympathetic distribution could be expected from epidural analgesia. Thus, any spinal or epidural block with surgical analgesia to the mid thoracic level, or above, is likely to involve the cardiac sympathetic nerves.

It is suggested from these findings that the physiological effects of epidural analgesia should be extended to include changes in the central as well as peripheral circulation. The consequences of these changes are mild in fit, resting subjects, but may become increasingly important in clinical situations in which the blood flow is failing to meet the demands. Likewise, the range of pharmacological replacement therapy should be broad enough to include both a chronotropic and inotropic effect on the heart as well as on the peripheral vascular beds. A rational safe clinical use of this valuable analgesic technique should consider the physiological and pharmacological consequences of these alterations in cardiac performance.

\section{SUMMary}

In order to isolate and identify the extent of cardiocirculatory changes following epidural analgesia, six fit preoperative patients were studied in the control state and after upper thoracic epidural block. Cardiocirculatory dynamics were assessed by measuring arterial and central venous pressures, heart rate, and cardiac output (Indocyanine dilution) and calculating total systemic vascular resistance and left ventricular work.

Following epidural blockade there was a significant reduction in cardiac index (16\%) and in heart rate, whereas the stroke volume remained constant in spite of a significant rise in central venous pressure $\left(1.9 \mathrm{~cm} . \mathrm{H}_{2} \mathrm{O}\right)$. A decline in arterial pressure (7\%) paralleled the reduction in minute flow. It is concluded that upper thoracic epidural analgesia reduces cardiac performance by interfering with fundamental cardiac mechanisms in two ways: firstly, by slowing the heart rate, and secondly, by reducing the myocardial response to its filling pressure.

\section{RÉSUMNÉ}

Afin d'isoler et d'identifier l'étendue des changements cardio-circulatoires consécutifs à une analgésie épidurale, on a étudié six malades en bonne santé durant l'analgésie et après le bloc épidural thoracique. La dynamique cardio-vasculaire a été évaluée en mesurant la pression artérielle et la pression veineuse centrale, la vitesse du cœur et le débit cardiaque (dilution à l'Indocyanine) et en calculant la résistance vasculaire systémique totale et le travail du ventricule gauche.

A la suite du blocage épidural, il y eut une diminution importante de l'Index 
cardiaque (16\%) et de la vitesse du cour, pendant que le volume systolique demeurait constant en dépit d'une élévation importante de la pression veineuse centrale $(1.9 \mathrm{~cm}$. d'eau). La baisse de la pression artérielle (7\%) a été proportionnelle à la diminution du volume minute. On a conclu que l'analgésie épidurale thoracique haute diminue le rendement cardiaque en touchant deux mécanismes cardiaques fondamentaux: d'abord en ralentissant la vitesse du cœur, puis en diminuant la contractilité du myocarde.

\section{REFERENCES}

1. Greene, N. M. Physiology of Sympathetic Denervation. Ann. Rev. Med. 13: 87 (1962).

2. Lr, T. H.; Skmosato, S.; \& ETsTEN, B. E. Methoxamine and Cardiac Output in Nonanesthetized Man and during Spinal Anesthesia. Anesthesiology. 26: 21 (1965).

3. Sancetta, S. M.; Lyns, R. B.; Srmerone, F. A.; \& ScotT, R. W. Hemodynamic Changes Following Spinal Anaesthesia. Circulation. 6: 559 (1952).

4. Ward, R. J.; Bonica, J. J.; Freund, F. G.; Aramatsu, T.; Danzjger, F.; \& Enclegson, S. Epidural and Subarachnoid Anesthesia: Cardiovascular and Respiratory Effects. J.A.M.A. 191 : 275 (1965).

5. MacLean, L. D.; Duff, J. H.; Scott, H. M.; \& Prretz, D. I. Treatment of Shock in Man Based on Hemodynamic Diagnosis. Surg. Gyn. Obst. 120: 1 (1965).

6. Bruce, T. A. \& Chapman, C. B. Left Ventricular Residual Volume in the Intact and Denervated Dog Heart. Circulation Res. 27 : 379 (1965).

7. Donald, D. E. \& ShepherRd, J. T. Response to Exercise in Dogs with Cardiac Denervation. Amer. J. Physiol. 205: 393 (1983).

8. Epstren, S. E.; Robinson, B. F.; Kafluen, R. L.; \& Braunwald, E. Effects of Betaadrenergic Blockade on the Cardiac Response to Maximal and Submaximal Exercise in Man. J. Clin. Invest. 44: 1745 (1965).

9. Kahler, R. L.; GaffNex, T. E.; \& Braunwaid, E. The Effects of Autonomic Nervous System Inhibition on the Circulatory Response to Muscular Exercise. J. Clin. Invest. 41: 1981 (1962).

10. Bromage, P. R. Spread of Analgesia Solutions in the Epidural Space and Their Site of Action. Brit. J. Anaesth. 34: 161 (1962).

11. Lewis, L. W. Evaluation of Sympathetic Activity Following Chemical or Surgical Sympathectomy. Anesth. \& Analg. $34: 334$ (1955).

12. Grick, G. \& Braunwain, E. Relative Roles of the Sympathetic and Parasympathetic Nervous Systems in the Reflex Control of Heart Rate. Circ. Res. 16: 363 (1965).

13. Kinnison, G. L.; Breeden, C. J.; Carmack, R. M.; Ballard, B. M.; Med, P. J.; \& HemcngWAY, A. Reflex Changes in Heart Rate and Ventilation Induced by Central Blood Pressure Changes. Amer. J. Physiol. 208: 1222 (1965).

14. Braunwald, E. The Control of Ventricular Function in Man. Brit. Heart J. 27: 1 (1965).

15. Sonnenblick, E. H.; Braunwald, E.; Williams, J. F.; \& Gircx, G. Effects of Exercise on Myocardial Force-Velocity Relations in Intact Unanesthetized Man: Relative Roles of Changes in Heart Rate, Sympathetic Activity, and Ventricular Dimensions. J. Clin. Invest. 44: 2051 (1965).

16. Ross, J.; Frafrm, C. J.; \& Braunwald, E. Influence of Carotid Baroceptors and Vasoactive Drugs on Systemic Vascular Volume and Venous Distensibility. Circ. Res. 9: 75 (1961).

17. Braunwald, E. \& CFmsex, C. A. The Adrenergic Nervous System in the Control of the Normal and Failing Heart. Proc. Roy. Soc. Med. 58: 1063 (1965).

18. Gafrney, T. E. \& BraUnwadd, E. The Importance of the Adrenergic Nervous System in the Support of Circulatory Function in Patients with Congestive Heart Failure. Amer. J. Med. 34: 320 (1963).

19. CRowell, J. W. \& GuYton, A. C. Eviderice Favoring a Cardiac Mechanism in Irreversible Hemorrhagic Shock. Amer. J. Physiol. 201: 893 (1961).

20. Braunwaid, E.; Mason, $O$. T.; \& Ross, J. Studies on the Cardiocirculatory Actions of Digitalis. Medicine. 44: 233 (1965).

21. Clowes, G. H. A.; Dex Guercio, L. R.; \& BARWInsKry, J. The Cardiac Output in Response to Surgical Trauma. Arch. Surg. $81: 212$ (1960).

22. Bromage, P. R.; Joyax, A. C.; \& Binnex, J. C. Local Anaesthetic Drugs: Penetration from the Spinal Extradural Space into the Neuraxis. Science. 140: 392 (1963). 